\title{
MOLECULAR DIVERSITY OF TWO-SPOTTED SPIDER MITE (TETRANYCHUS URTICAE) IN APPLE ORCHARDS ACROSS POLAND AND ITS POTENTIAL LINK WITH THE RESISTANCE TO METI-ACARICIDES
}

\author{
Tomasz JĘCZ ${ }^{1}$, Małgorzata KORBIN ${ }^{2 *}$, Damian GORZKA ${ }^{2}$, Abdel-Rahman A. MOHAMED ${ }^{3}$, \\ Remigiusz OLSZAK ${ }^{4}$ \\ ${ }^{1}$ University of Lodz, Faculty of Biology and Environmental Protection, Lodz, Poland \\ ${ }^{2}$ Research Institute of Horticulture, Skierniewice, Poland \\ ${ }^{3}$ Department of Agriculture, Minia University, Egypt \\ ${ }^{4}$ Institute of Applied Pomology, Kopana, Poland
}

Received: November 2018; Accepted: February 2019

\begin{abstract}
Two-spotted spider mite (Tetranychus urticae, Koch) possess tremendous ability to develop resistance to pest control chemicals. Hence, although METI-acaricides are quite new group of pesticides, the resistance to this chemicals may shortly become a serious obstacle in two-spotted spider mite management. In presented study, molecular and phenotypic diversity of three laboratory strains and seven T. urticae populations collected from pest-protected apple orchards were analysed in reference to METI-acaricides resistance. The inter-population molecular diversity analysis with a set of RAPD markers revealed 6 populations to be in close relation to susceptible reference strain (GSS). Only one population turned out to be linked relatively close with METI-acaricides resistant strain (Akita). Simultaneously, the results of biological test showed similar relation among the analysed populations, according to the resistance incidence ratio. Obtained results suggest that METI-acaricides resistance trait in two-spotted spider mite is likely to be determined at genomic level and may be considered as an initial stage for developing molecular biology tools for early detection of METI-acaricides resistance in T. urticae populations.
\end{abstract}

Keywords: Tetranychus urticae, apple, RAPD polymorphism, acaricides, bioassay

\section{INTRODUCTION}

The two-spotted spider mite (Tetranychus urticae Koch), the member of the order Acari, the class Arachnida, and the family Tetranychidae, represents one of the most polyphagous arthropod herbivores. It can feed on more than 1,100 plant species from more than 140 different plant families, including species producing toxic compounds in tropical and temperate zones (Bolland et al. 1998). As a one of the major pests in greenhouse and field production, $T$. urticae destroys annual and perennial crops such as tomatoes, peppers, cucumbers, strawberries, maize, soy, apples, grapes and citrus (Jeppson et al. 1975). Spider mite damages plants by sucking plant juices from leaves cells causing white to yellow stippling to appear on foliage as chlorophyll is removed, and heavily infested annuals are very often killed (Campbell et al. 1990; Park \& Lee 2002).

Invasive capability of $T$. urticae in world agriculture and its capacity to adapt to stresses occurring in the environment are associated with several unique characters of this mite, i.e. high liability to mutate (Van Leeuwen et al. 2010), high reproduction rate and fecundity, as well as haplo-diploid sex determination (Helle \& Bolland 1967). These traits favored to encourage the evolution and resulted in the most frequent incidents of resistance to pesticides among arthropods (Devine et al. 2001; Osakabe et al. 2009). Failures in the chemical control of spider mites caused by this resistance were reported for such compounds as organophosphates, dicofol, 
and abamectin only a few years after their introduction (Cranham \& Helle 1985; Campos et al. 1995). Resistance of Tetranychus species to new group of acaricides, belonging to the mitochondrial electron transport inhibitors (METIs) (Lümmen 1998), was firstly described in Japan (Ozawa 1994). Later on, the resistance of $T$. urticae to this kind of acaricides was reported in Belgium (Bylemans \& Meurrens 1997), Australia (Herron \& Rophail 1998), and England (Devine et al. 2001). Only a few years ago, the incidence of METI-acaricides resistant twospotted spider mites was revealed in apple orchards in Poland (Maciesiak \& Olszak 2011).

Although the putative biochemical mechanisms of METI-acaricide resistance have been proposed (Kim et al. 2004, 2006; Van Pottelberge et al. 2008), the molecular background of this phenomenon remains unknown. The results of conventional genetic studies indicate that METI-acaricides resistance in two-spotted spider mite may be controlled by single major gene (Stumpf \& Nauen 2001; Devine et al. 2001; Sato et al. 2004, Ay \& Kara 2011) however, due to the incompletely dominant inheritance mode, the subsistence of additional genetic determinants cannot be excluded. Moreover, recent sequencing and annotation of T. urticae genome revealed the gene families associated with detoxification to be expanded in comparison with other insects (Grbić et al. 2011).

The aim of presented study was to determine the genetic diversity of $T$. urticae collected from apple orchards across Poland, as well as to find out whether any interrelation between the molecular differences and occurrence of METI-acaricides resistance can be remarked.

\section{MATERIAL AND METHODS}

\section{Pest material}

Sets of two-spotted spider mite individuals were collected from seven apple orchards located in different regions of Poland (Fig. 1). In all these orchards METI-acaricides treatment had been applied for no shorter period than five seasons before mite sampling. A Japanese strain (Akita) with high level of cross-resistance to all commercially available METI-acaricides, as well as a susceptible strain
(GSS) of T. urticae were kindly provided by the Bayer CropScience group in Monheim (Germany). A Polish strain (PL) was originally collected from apple orchard and maintained in the laboratory under no further selection pressure in long-term breeding system, since late 1970s. Only female individuals (diploids), selected basing on adequate morphological features, were subjected to analyses.

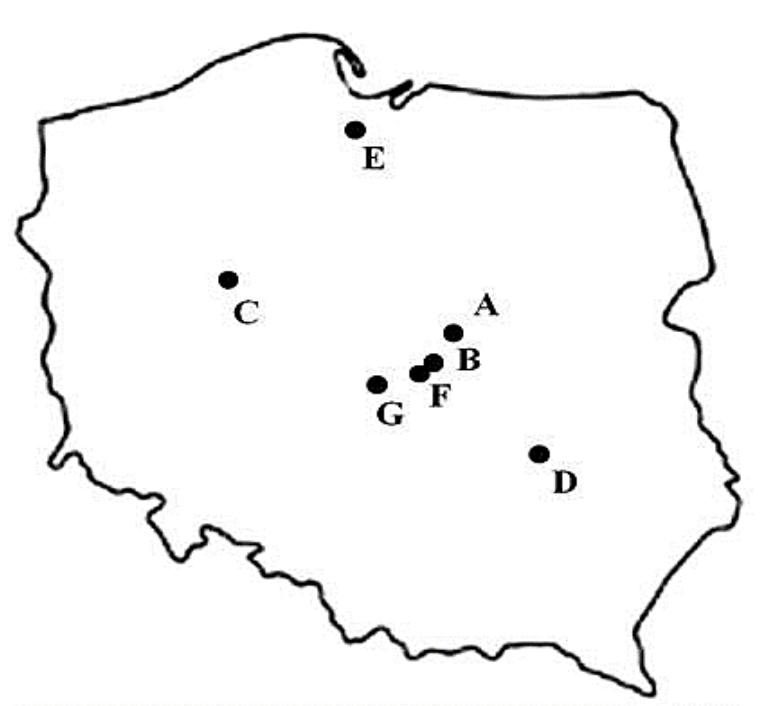

Fig. 1. Location map of the orchards (letters from A to G) in which $T$. urticae samples were collected in the biggest apple production regions across Poland

\section{Bioassays}

The commercial formulations of fenazaquin (Magus $200 \mathrm{SC}, 200 \mathrm{~g}$ a.i. $\mathrm{dm}^{-3}$ ), fenpyroximate (Ortus 05 SC, 51,2 g a.i. $\mathrm{dm}^{-3}$ ), and pyridaben (Sanmite 20 WP, $200 \mathrm{~g}$ a.i. $\mathrm{dm}^{-3}$ ) were used in the biological test. The concentrations of spraying solutions were calculated basing on the highest field concentrations permitted by the pest-control programme. Before the acaricide treatment, individuals were trapped within the gel barrier area on the upper side of apple leaf. Leaves were then placed in Petri dishes and sprayed with $2 \mathrm{ml}$ acaricide solution (control samples with distilled water) at 2 bar pressure in Potter laboratory spray tower. Individuals from each sample (10 adult females) were subjected to spraying with each acaricide in four replicates. The leaves with pests were subsequently transferred to the climate control chambers at $25{ }^{\circ} \mathrm{C}, 50-60 \%$ relative humidity and 16:8 h (light: darkness) photoperiod. The number of survivors/dead individuals was 
recorded after three days. Tested individuals were scored as living (1) if able to move normally, or dead (0) if immobile after prodded with paintbrush.

\section{DNA extraction}

Each laboratory strain and field location subjected to this study was represented by three samples, each containing fifteen female individuals pooled together. DNA was extracted from spider mite tissues according to the method developed by Dermauw et al. (2009). Briefly, the mechanically disrupted individuals were incubated for 30 minutes at the temperature $60{ }^{\circ} \mathrm{C}$ in extraction buffer containing $2 \%$ SDS, $400 \mathrm{mM} \mathrm{NaCl}, 200 \mathrm{mM}$ Trizma base and $10 \mathrm{mM}$ EDTA. Nucleic acids were purified with phenol/chloroform/isoamyl alcohol mix $(25: 24: 1)$, precipitated with isopropanol $(0.7 \mathrm{v} / \mathrm{v})$, pelleted by centrifugation (30 min, $12000 \mathrm{rpm}, 4^{\circ} \mathrm{C}$ ), and then dissolved in $50 \mu \mathrm{l}$ of $\mathrm{H}_{2} \mathrm{O}$.

\section{PCR conditions}

RAPD-PCR was performed in a volume of $20 \mu \mathrm{l}$. The reaction mixture contained $1 \times$ PCR Buffer, $2 \mathrm{mM} \mathrm{MgCl} 2,0.2 \mathrm{mM}$ of each dNTP, $0.2 \mu \mathrm{M}$ of RAPD primer, $1 \mathrm{U}$ AmpliTaq Gold Polymerase (Applied Biosystems) and 10 ng of DNA template. Reactions were carried out in TProfessional thermal cyclers (Biometra) with the following thermal profile, preceded by initial DNA denaturation $(600 \mathrm{~s}$ at $\left.94{ }^{\circ} \mathrm{C}\right): 60 \mathrm{~s}$ at $94{ }^{\circ} \mathrm{C}, 60 \mathrm{~s}$ at $40{ }^{\circ} \mathrm{C}, 120 \mathrm{~s}$ at $72{ }^{\circ} \mathrm{C}$ (48 cycles), followed by final elongation (120 s at $\left.72{ }^{\circ} \mathrm{C}\right)$.

Two hundred and forty arbitrary primers from series: OPA, OPB, OPC, OPD, OPE, OPF, OPG, OPH, OPJ, OPK, OPL, OPM (Operon Technology, 20 decamers within each series) were used in RAPD reactions conducted on the DNA templates isolated from Akita, GSS and PL samples. Subsequently, RAPD reactions for field-derived populations were run with 53 primers that generated polymorphic amplicons (band patterns) for the laboratory strains. PCR products were separated in $1.5 \%$ agarose gel, dyed with ethidium bromide and observed under UV light. Band patterns reproducible in at least two of three technical RAPD-PCR replicates were assumed informative and subjected to statistical analysis. Unambiguous bands (amplicons) of size lower than $2 \mathrm{~kb}$ and higher than $100 \mathrm{bp}$ were scored as 1 , while the unclear or absent bands as 0 .

\section{Data analysis}

RAPD-PCR resultant binary (0/1) matrixes of band absence/presence throughout loci were used for band frequency statistics, genetic distance and molecular variance (AMOVA) (Excoffier et al. 1992) analyses. All statistical calculations for RAPD-PCR results were performed with use of FAMD (Schlüter \& Harris 2006) and GenAlEx 6.5 (Peakall \& Smouse 2006, 2012) software packages. The PhiPT parameter resulting from AMOVA is explained as a relation of the among-population (AP) variance and the sum of among- and within-population (WP) variance components $(\mathrm{PhiPT}=\mathrm{AP} /[\mathrm{WP}+\mathrm{AP}])$. The probability $(\mathrm{P})$ of a random PhiPT value greater than equal to the observed data value was based on 999 permutations across full data set. The level of similarity between analyzed genetic pools was estimated by comparing DNA band pattern scores using Jaccard's coefficient of similarity (with the distance transformation $d=1-s$ ) (Tan et al. 2005). The resulting genetic distance values calculated among and within sampled populations were used as input for Unweighted Pair Group Method with Arithmetic Mean (UPGMA)-based (Sneath \& Sokal 1973) cluster analysis.

The survivors/dead individuals scores obtained after treatment with three acaricides were combined in one dataset within each population/strain. UPGMA hierarchical clustering was performed basing on $\mathrm{Eu}$ clidean distance matrix (where $\mathrm{d}^{\prime}=\mathrm{d}$ ).

\section{RESULTS}

\section{RAPD-based analysis of laboratory strains of two-spotted spider mite}

One hundred ninety four out of the 240 tested RAPD primers generated reproducible bands on the templates of DNA isolated from Akita, GSS and PL samples. Bands polymorphic between the strains were amplified in reaction with 146 primers (Table 1). In PCR with these primers, a total of 876, 874 and 984 bands were generated for Akita, GSS and PL laboratory strains, respectively, arranged in 1338 loci. One thousand two hundred thirty three polymorphic bands were found in all data set, of which 173 bands were specific for Akita, 99 for GSS and 171 for PL samples. Fifty percent 
of polymorphic loci was recorded within PL population, whereas within Akita and GSS populations the values of $45.7 \%$ and $43.3 \%$ were noted, respectively. As AMOVA analysis showed, $68 \%$ of the total molecular variance was attributable to withinstrains differences, while $32 \%$ to genetic variation among the strains. The PhiPT $=0.31(\mathrm{P}=0.002)$ indicated that the strains differed significantly from each other. Pair wise comparisons between each single sample of the three strains resulted in standard Jaccard's coefficient matrix of genetic distances, which was used subsequently in UPGMA cluster analysis to generate a dendrogram depicting the RAPD-based similarity among strains (Fig. 2). The smallest distance (average for the three samples within the strain) was revealed between GSS and PL (0.612), while between Akita and PL strains the highest distance value was noted (0.674). The analysis performed within each strain showed the highest distance diversity in Akita (0.207) and the lowest in GSS (0.117).

Table 1. RAPD primers generating polymorphic amplicons in PCR conducted on the template of Akita, GSS and PL genetic pools

\begin{tabular}{|c|c|}
\hline $\begin{array}{c}\text { Primer } \\
\text { series }\end{array}$ & Number of primer \\
\hline OPA & $\begin{array}{l}01,02,03,05,08,10,11,12,13,15,16,17 \\
18,19,20\end{array}$ \\
\hline OPB & $04,05,07,08,11,12,15,17,18,19,20$ \\
\hline $\mathrm{OPC}$ & $01,04,05,06,07,08,10,11,12,20$ \\
\hline OPD & $02,03,05,11,12,15,16,20$ \\
\hline OPE & $01,02,04,06,07,11,12,14,15,16,19,20$ \\
\hline OPF & $\begin{array}{l}01,04,06,07,08,09,10,11,12,13,14,15 \\
16,17\end{array}$ \\
\hline OPG & $02,03,04,08,10,11,13,14,15,18,19$ \\
\hline $\mathrm{OPH}$ & $05,08,09,12,13,17,18,19$ \\
\hline OPJ & $\begin{array}{l}04,05,07,10,11,12,13,14,15,16,18,19, \\
20\end{array}$ \\
\hline OPK & $\begin{array}{l}01,03,04,06,07,08,09,11,12,13,15,16 \\
17,18,19,20\end{array}$ \\
\hline OPL & $\begin{array}{l}02,03,04,05,06,08,09,10,12,14,15,17, \\
18\end{array}$ \\
\hline OPM & $\begin{array}{l}01,02,03,05,06,07,09,11,12,13,14,15 \\
18,19,20\end{array}$ \\
\hline
\end{tabular}

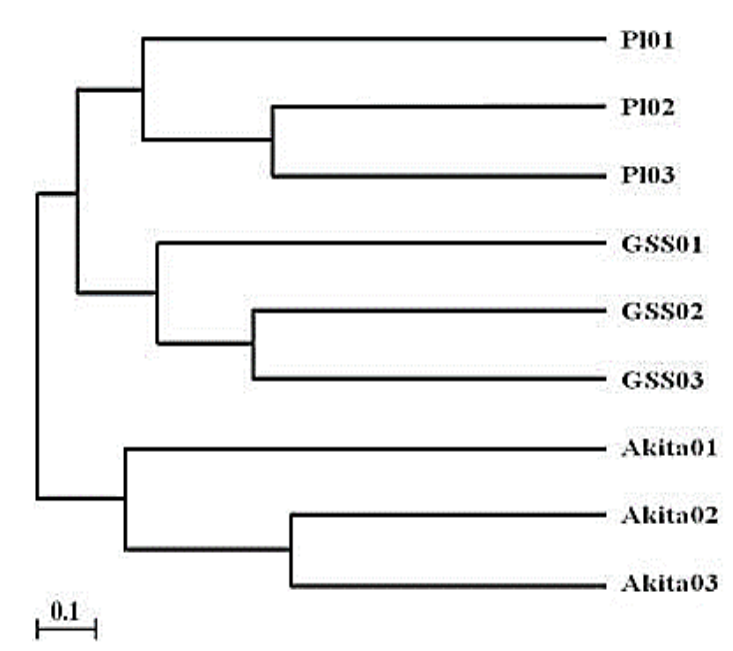

Fig. 2 Dendrogram of genetic relationship of sub-samples of Akita, GSS and PL strains based on UPGMA cluster analysis of Jaccard's coefficient of RAPD distance matrix

\section{RAPD-based analysis of $T$. urticae field popula- tions}

Analysis of amplicons specific for Akita-, GSS- and PL (strain-discriminating) revealed differences between populations collected from seven locations, as well as between samples within each population. The laboratory strains Akita (resistant) and GSS (susceptible to METI-acaricides) were included in this analysis as reference. The total number of obtained bands ranged from 156 (population C) to 171 (population A), with an average of 163 bands per population, distributed in 253 loci. Two hundred and nine polymorphic bands were found in all data set. The percentage of within-population polymorphic loci ranged from 13.8 (population $\mathrm{C}$ ) to 36.0 (population D). AMOVA analysis ascribed $46 \%$ of the total molecular variance to within-populations variation, whereas $54 \%$ to the differences among populations, with PhiPT $=0.55(\mathrm{p}=0.001)$ proving the populations significantly different from each other. The Jaccard's coefficient matrix of genetic distances (data not shown) and subsequent UPGMA cluster analysis (Fig. 3) revealed the relatively short average distance between A, B, C, D, E and G populations, ranging from 0.324 to 0.499 . The distance between $\mathrm{F}$ and other field populations varied between 0.451 and 0.541. Simultaneously, Akita reference strain turned out to stay in a far average distance from all (ranging from 0.522 to 0.618 ) but $F$ 
(0.405) field populations. On the contrary, the distance between GSS reference strain appeared to be relatively small (ranging from 0.501 to 0.540 ) to all field populations except from $\mathrm{F}(0.612)$ and the laboratory strain Akita (0.565). The analysis of genetic distance between the samples within each field population revealed the highest range in $\mathrm{D}(0.107)$ and the lowest in C orchard (0.034).

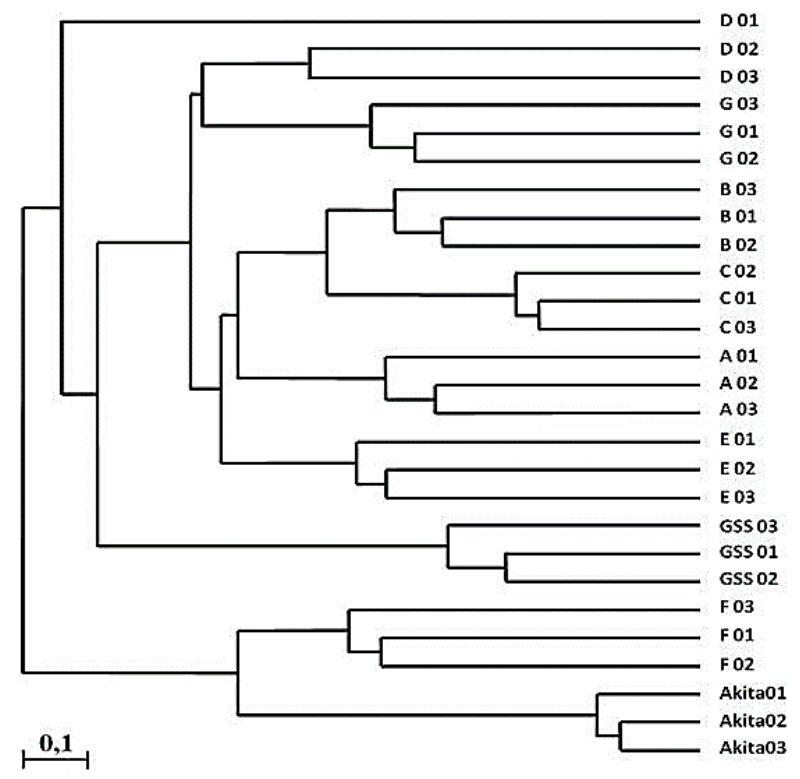

Fig. 3 Dendrogram of genetic relationship of samples of T. urticae field populations and reference laboratory strains obtained from UPGMA cluster analysis of Jaccard's coefficient RAPD distance matrix. The letters from $A$ to $G$ correspond to investigated orchards/field populations

\section{METI-acaricides resistance in field populations and laboratory strains of $T$. urticae}

Depending on field/laboratory population analysed, the diverse number of METI-acaricide resistant individuals was observed in bioassays. Considering a combined outcome for all three acaricides used, the highest ratio of spraying-survivors was observed in Akita (99.1\%), and the lowest in GSS reference strain (4.2\%). Among the field populations $93.2 \%$ of $\mathrm{B}$ and $87 \%$ of $\mathrm{F}$ individuals endured the test, whilst only about $4.5 \%$ of survivors were found in $\mathrm{D}$ and $\mathrm{E}$ populations. The distances matrix and UPGMA-based cluster analysis revealed the A, C, D, E and $\mathrm{G}$ populations to stay in a relatively small distance to each other, ranging from 0.048 to 0.225 .
Populations B and F appeared to be clustered together (with the distance value 0.076 between them) remotely to the remaining field populations (average distance between $\mathrm{B}, \mathrm{F}$ and the other populations from 0.303 to 0.479 ). Simultaneously, the small distance between Akita reference strain and populations B and F (0.079 and 0.077 , respectively) was noted, while between Akita and A, C, D, E and G field populations relatively high distance values were found (ranging from 0.345 to 0.518 ). At the same time, the distance between GSS reference strain and A, C, D, E, G field populations appeared to be relatively small (varying between 0.060 and 0.225), whereas the higher distance values between GSS and B, F populations ( 0.550 and 0.489 , respectively), as well as GSS and Akita strain (0.559) were observed (Fig. 4).

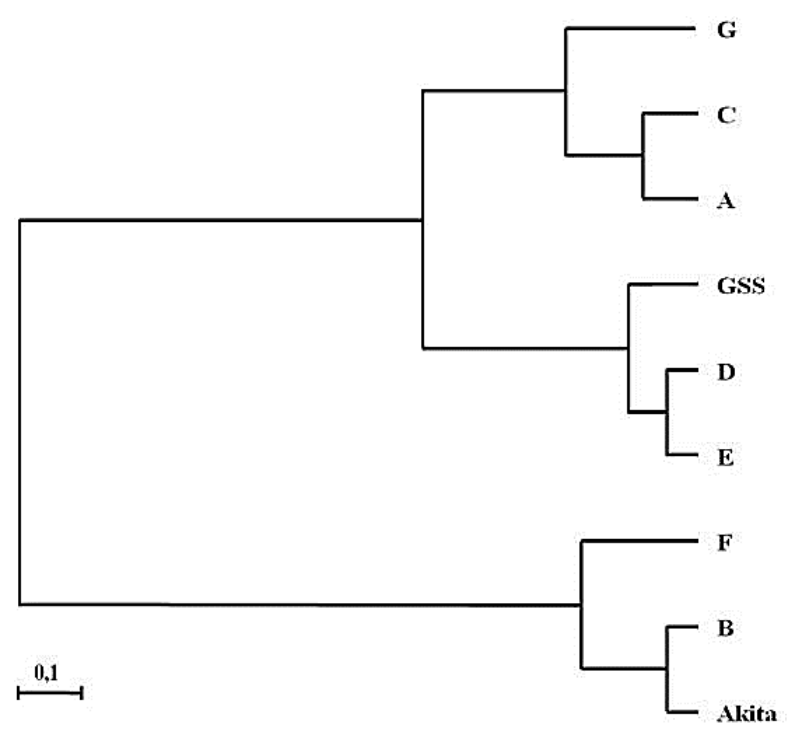

Fig. 4 Dendrogram of relationship of T. urticae field populations and reference laboratory strains obtained from UPGMA cluster analysis of Euclidean distance matrix for resistance/susceptibility to METI-acaricides incidences. The letters from A to $\mathrm{G}$ correspond to investigated orchards/field populations

\section{DISCUSSION}

RAPD-PCR results obtained revealed considerable molecular variability between laboratory and field populations of T. urticae. However, the significant differences were also found within each tested population. Similar phenomenon was reported by 
Shah et al. (2002), who suggested the genetic heterogeneity of $T$. urticae females as a one of possible explanations for intra-population RAPD-PCR results variation. Although no relevant molecular divergence within $T$. urticae population was detected in glasshouse trial by Navajas et al. (2002), what can be explained as a result of intensive inbreeding in isolated environment, the two-spotted spider mite genetic differentiation was revealed in natural field conditions. Carbonnelle et al. (2007) observed high percentage of total microsatellite variation within T. urticae populations along north-south transect of Europe. Similarly, in Tetranychus turkestani Bailly et al. (2004) observed the higher level of microsatellite diversity more at intra- than at inter-population level, suggesting that mites colonizing given locality originate from diverse sources. Congruous results were obtained for Panonychus citri (Tetranychidae), for which in natural habitat (citrus groves) the higher level of genetic diversity among specimens in close proximity was noted, owing to the limited dispersion ability (Osakabe et al. 2005). This conclusion was recently supported by AguilarFenollosa et al. (2016), who revealed the co-existence of distinct genetic clusters of Tetranychus urticae in the grass cover and the tree canopies within the same citrus grove, showing that the habitat (host) adaptation impedes the dispersal of this mite. However, the investigation on the mechanism of gene flow of the two-spotted spider mite in apple orchards proved that high population density increases the migration rate among spatially distant breeding colonies (Uesugi et al. 2009). Additionally, the evidence for inbreeding-avoidance behavior in dense populations of T. urticae has been found by Yoshioka and Yano (2014). Hence, high density of population during sample collection time, where outbreeding and gene flux are unconstrained more likely than among distant populations, together with the mixed origin of specimens within population, may provide an explanation for the genetic divergence observed herein.

Along with substantial within-population molecular variation, the measurable divergence between $T$. urticae reference laboratory strains (Akita and GSS) and field populations, as well as laboratory strains and field populations all together was detected in presented study. The UPGMA analyses of RAPD-derived results confirmed the distribution of subjected populations into two distinct clusters, one comprising Akita and the population collected from F location, and the second consisting of GSS and the remaining 6 field populations. Such clustering mode indicates relatively close relationship between $F$ population and Akita strain, what suggests these two may share the common trait of METI-acaricide resistance. And vice versa, the GSS-containing cluster may potentially bonds the populations highly susceptible to METI-acaricides. Any intercluster heterogeneities observed concurrently, particularly the split between Akita and F, as well as between GSS and the other 6 field populations, become explicable when the geographically distant origins of Akita (Japan) (Ako et al. 2006), GSS (Germany) (Nauen et al. 2001), and field populations from different regions of Poland are taken into account. According to Li et al. (2009) and Sun et al. (2012) findings, the relation between geographical distance of T. urticae populations and their genetic differentiation is significantly strong. Certainly, considering the "whole-genome" character of RAPD markers, the contribution of the overall detected RAPD similarity/diversity to any other phenotypic differences between the subjected populations must be taken into account. On the other hand, many authors reported usefulness of RAPD-PCR technique for detection of genetic polymorphism between insecticide-resistant and susceptible pest populations. It was confirmed, among others, for Anopheles barbirostris (Laltanpuii et al. 2011), Liriomyza trifolii (Ferguson \& Pineda 2010) and Spodoptera litura (Janarthanan et al. 2003). As yet the only report on potential of random decamers for monitoring $T$. urticae insecticide resistance was dedicated mostly to methodological and technical considerations (Shah et al. 2002).

Thus, the remarkably big genetic distance between Akita and GSS strains suggests that at least part of the genetic divergence between these two contributes to the METI-acaricide resistance/susceptibility phenotype. This assumption is additionally supported by the close genetic relationship of GSS with PL laboratory strains, which both had not been subjected to acaricide selection pressure. Most 
importantly, however, the among-population molecular variance and the divergence of pest resistance observed in biological test appeared to stay in agreement, when compared for particular population. GSS- and Akita-proximal UPGMA clusters compositions turned out to be similar, independently of data source: phenotypic or molecular, although the distance values between strains and populations differed substantially in these two corresponding data sets. The only exception was population derived from location $\mathrm{B}$, which according to molecular analyses was localized nearby GSS reference, while the phenotypic data analysis placed this population in close proximity of Akita. This exception may be explained by the hypothesis that the molecular mechanism of METI-acaricide resistance operating in population B differs from that characteristic for Akita strain and population F. The support for this hypothesis comes from Van Pottelberge et al. (2009), who suggested the existence of alternative resistance mechanisms in $T$. urticae basing on genetic studies, although no molecular evidence for that has been found thus far. The existence of such alternative mechanism seems probable especially, as the inheritance mode (mono- vs. polygenic) of the resistance to particular class of acaricides in T. urticae populations may differ depending on the region (Osakabe et al. 2009).

The results presented herein demonstrate high molecular diversity in T. urticae collected from Polish apple orchards. Some (unidentified) part of the among-population component of this diversity, after juxtaposed with the phenotypic bioassay observations, may be presumed responsible for differential METI-acaricides resistance of pest populations. Following the emerging need for systematic monitoring of apple orchards in terms of the occurrence of acaricide resistance phenomenon, obtained results can be considered as a preliminary for developing molecular biology tools for early detection of METI-acaricides resistance in twospotted spider mite populations. Nevertheless, the elucidation of actual molecular mechanisms underlying this type of resistance, which will allow to generate the proper "resistance-linked" molecular markers, requires further, more profound investigation.

\section{Acknowledgments}

The study was supported by Polish National Centre for Research and Development, grant number N R12-0081-10: "Resistance of Tetranychus urticae (Koch) to METI-acaricides - assessment of risk in apple orchards in Poland using classical, molecular and biochemical methods."

\section{REFERENCES}

Aguilar-Fenollosa E., Rey-Caballero J., Blasco J.M., Segarra-Moragues J.G., Hurtado M.A., Jaques J.A. 2016. Patterns of ambulatory dispersal in Tetranychus urticae can be associated with host plant specialization. Experimental and Applied Acarology 68: 1-20. DOI: 10.1007/s10493-015-9969-1.

Ako M., Poehling H.-M., Borgemeister Ch., Nauen R. 2006. Effect of imidacloprid on the reproduction of acaricide-resistant and susceptible strains of Tetranychus urticae Koch (Acari: Tetranychidae). Pest Management Science 62: 419-424. DOI: 10.1002/ps. 1182 .

Ay R., Kara F.E. 2011. Toxicity, inheritance of fenpyroximate resistance, and detoxification-enzyme levels in a laboratory-selected fenpyroximate-resistant strain of Tetranychus urticae Koch (Acari: Tetranychidae). Crop Protection 30: 605-610. DOI: $10.1016 /$ j.cropro.2010.11.012.

Bailly X., Migeon A., Navajas M. 2004. Analysis of microsatellite variation in the spider mite pest Tetranychus turkestani (Acari: Tetranychidae) reveals population genetic structure and raises questions about related ecological factors. Biological Journal of the Linnean Society 82: 69-78. DOI: 10.1111/j.1095-8312.2004.00316.x.

Bolland H.R., Gutierrez J., Flechtmann C.H.W. 1998. World catalogue of the spider mite family (Acari: Tetranychidae). Brill, Leiden, The Netherlands, 392 p.

Bylemans D., Meurrens F. 1997. Anti-resistance strategies for two-spotted spider mite, Tetranychus urticae (Acari: Tetranychidae), in strawberry culture. Acta Horticulturae 439: 869-876. DOI: 10.17660/actahortic.1997.439.142.

Campbell R.J., Grayson R.L., Marini R.P. 1990. Surface and ultrastructural feeding injury to strawberry leaves by the twospotted spider mite. HortScience 25: 948-951. DOI: 10.21273/hortsci.25.8.948

Campos F., Dybas R.A., Krupa D. 1995. Susceptibility of twospotted spider mite (Acari: Tetranychidae) populations in California to abamectin. Journal of Economic Entomology 88: 225-231. DOI: 10.1093/jee/88.2.225. 
Carbonnelle S., Hance T., Migeon A., Baret P., Cros-Arteil S., Navajas M. 2007. Microsatellite markers reveal spatial genetic structure of Tetranychus urticae (Acari: Tetranychidae) populations along a latitudinal gradient in Europe. Experimental and Applied Acarology 41: 225-241. DOI: 10.1007/s10493007-9068-z.

Cranham J.E., Helle W. 1985. Pesticide resistance in Tetranychidae. In: Helle W., Sabelis M.W. (Eds.), Spider mites: Their biology, natural enemies and control. Elsevier, Amsterdam, The Netherlands, pp. 405-421.

Dermauw W., Van Leeuwen T., Vanholme B., Tirry L. 2009. The complete mitochondrial genome of the house dust mite Dermatophagoides pteronyssinus (Trouessart): a novel gene arrangement among arthropods. BMC Genomics 10; 107, 20 p. DOI: 10.1186/1471-2164-10-107.

Devine G.J., Barber M., Denholm I. 2001. Incidence and inheritance of resistance to METI-acaricides in European strains of the two-spotted spider mite (Tetranychus urticae) (Acari: Tetranychidae). Pest Management Science 57:443-448. DOI: 10.1002/ps.307.

Excoffier L., Smouse P.E., Quattro J.M. 1992. Analysis of molecular variance inferred from metric distances among DNA haplotypes: Application to human mitochondrial DNA restriction data. Genetics 131: 479-491.

Ferguson S., Pineda O. 2010. Putative polymerase chain reaction markers for insecticide resistance in leafminer Liriomyza trifolii (Diptera: Agromyzidae) to cyromazine and abamectin. Journal of Economic Entomology 103: 2197-2203. DOI: 10.1603/ec10073.

Grbić M., Van Leeuwen T., Clark R.M., Rombauts S., Rouzé P., Grbić V. et al. 2011. The genome of Tetranychus urticae reveals herbivorous pest adaptations. Nature 479: 487-492. DOI: 10.1038/nature 10640.

Helle W., Bolland H.R. 1967. Karyotypes and sex-determination in spider mites (Tetranychidae). Genetica 38: 43-53. DOI: 10.1007/bf01507446.

Herron G.A., Rophail J. 1998. Tebufenpyrad (Pyranica ${ }^{\circledR}$ ) resistance detected in two-spotted spider mite Tetranychus urticae Koch (Acari: Tetranychidae) from apples in Western Australia. Experimental and Applied Acarology 22: 633-641. DOI: 10.1023/a:1006058705429.

Janarthanan S., Seshadri S., Kathiravan K., Ignacimuthu S. 2003. Comparison of insecticide resistant and susceptible populations of Spodoptera litura Fab. Indian Journal of Biotechnology 2: 539-542.

Jeppson L.R., Keifer H.H., Baker E.W. 1975. Mites injurious to economic plants. University of California Press, Berkeley, USA, 614 p.

Kim Y.-J., Lee S.-H., Lee S.-W., Ahn Y.-J. 2004. Fenpyroximate resistance in Tetranychus urticae (Acari: Tetranychidae): cross-resistance and biochemical resistance mechanisms. Pest Management Science 60: 1001-1006. DOI: 10.1002/ps.909.

Kim Y.-J., Park H.-M., Cho J.-R., Ahn Y.-J. 2006. Multiple resistance and biochemical mechanisms of pyridaben resistance in Tetranychus urticae (Acari: Tetranychidae). Journal of Economic Entomology 99: 954-958. DOI: 10.1093/jee/99.3.954.

Lalțanpuii R., Zomouanpuii R., Hijam T., Gurusubramanian G., Kumar N.S. 2011. RAPD-PCR characterization of insecticide resistant and susceptible Anopheles species. Science Vision 11: 159-164.

Li T., Chen X.-L., Hong X.-Y. 2009. Population genetic structure of Tetranychus urticae and its sibling species Tetranychus cinnabaribus (Acari: Tetranychidae) in China as inferred from microsatellite data. Annals of the Entomological Society of America 102: 647. DOI: 10.1603/008.102.0412.

Lümmen P. 1998. Complex I inhibitors as insecticides and acaricides. Biochimica et Biophysica Acta 1364: 287-296. DOI: 10.1016/s00052728(98)00034-6.

Maciesiak A., Olszak R.W. 2011. Niepowodzenia w zwalczaniu przędziorków w sadach. Proceedings of the $54^{\text {th }}$ Polish Conference for Pomological Plants Protection, Ossa, Poland, pp. 97-100. [in Polish]

Nauen R., Stumpf N., Elbert A., Zebitz C.P.W., Kraus W. 2001. Acaricide toxicity and resistance in larvae of different strains of Tetranychus urticae and Panonychus ulmi (Acari: Tetranychidae). Pest Management Science 57: 253-261. DOI: 10.1002/ps. 280 .

Navajas M., Perrot-Minnot M.J., Lagnel J., Migeon A., Bourse T., Cornuet J.M. 2002. Genetic structure of a greenhouse population of the spider mite Tetranychus urticae: spatio-temporal analysis with microsatellite markers. Insect Molecular Biology 11: 157-165. DOI: 10.1046/j.13652583.2002.00320.x.

Osakabe M., Goka K., Toda S., Shintaku T., Amano H. 2005. Significance of habitat type for the genetic population structure of Panonychus citri (Acari: Tetranychidae). Experimental and Applied Acarology 36:25-40. DOI: 10.1007/s10493-005-1672-1. 
Osakabe Mh., Uesugi R., Goka K. 2009. Evolutionary aspects of acaricide-resistance development in spider mites. Psyche 2009, Article ID 947439, 11 p. DOI: 10.1155/2009/947439.

Ozawa A. 1994. Acaricides susceptibility of Kanzawa spider mite, Tetranychus kanzawai Kishida (Acarina: Tetranychidae) collected from tea fields in Chuuen and Ogasa district in Shizuoka prefecture. Tea Research Journal 1994(79): 1-14. DOI: 10.5979/cha.1994.1.

Park Y.-L., Lee J.-H. 2002. Leaf cell and tissue damage of cucumber caused by twospotted spider mite (Acari: Tetranychidae). Journal of Economic Entomology 95: 952-957. DOI: 10.1093/jee/95.5.952.

Peakall R., Smouse P.E. 2006. GENALEX 6: genetic analysis in Excel. Population genetic software for teaching and research. Molecular Ecology Notes 6: 288295. DOI: 10.1111/j.1471-8286.2005.01155.x.

Peakall R., Smouse P.E. 2012. GenAlEx 6.5: genetic analysis in Excel. Population genetic software for teaching and research - an update. Bioinformatics 28: 2537-2539. DOI: 10.1093/bioinformatics/bts 460 .

Sato M.E., Miyata T., Da Silva M., Raga A., De Souza Filho M.F. 2004. Selections for fenpyroximate resistance and susceptibility, and inheritance, crossresistance and stability of fenpyroximate resistance in Tetranychus urticae Koch (Acari: Tetranychidae). Applied Entomology and Zoology 39: 293 302. DOI: 10.1303/aez.2004.293.

Schlüter P.M., Harris S.A. 2006. Analysis of multilocus fingerprinting data sets containing missing data. Molecular Ecology Notes 6: 569-572. DOI: 10.1111/j.1471-8286.2006.01225.x.

Shah R., Armstrong K., Worner S.P., Chapman R.B. 2002. Investigation of a PCR-based method for insecticide resistance monitoring. Pakistan Journal of Biological Sciences 5: 1070-1073. DOI: 10.3923/pjbs.2002.1070.1073.

Sneath P.H.A., Sokal R.R. 1973. Numerical Taxonomy. The principles and practice of numerical classification. Freeman, San Francisco, USA, 573 p.
Stumpf N., Nauen R. 2001. Cross-resistance, inheritance, and biochemistry of mitochondrial electron transport inhibitor-acaricide resistance in Tetranychus urticae (Acari: Tetranychidae). Journal of Economic Entomology 94: 1577-1583. DOI: 10.1603/0022-0493-94.6.1577.

Sun J.-T., Lian Ch., Navajas M., Hong X.-Y. 2012. Microsatellites reveal a strong subdivision of genetic structure in Chinese populations of the mite Tetranychus urticae Koch (Acari: Tetranychidae). BMC Genetics 13; 8, 13 p. DOI: 10.1186/14712156-13-8.

Tan P.-N., Steinbach M., Kumar V. 2005. Introduction to data mining. Addison-Wesley Longman, USA, 769 p.

Uesugi R., Sasawaki T., Osakabe Mh. 2009. Evidence of a high level of gene flow among apple trees in Tetranychus urticae. Experimental and Applied Acarology 49: 281-290. DOI: 10.1007/s10493009-9267-x.

Van Leeuwen T., Vontas J., Tsagkarakou A., Dermauw W., Tirry L. 2010. Acaricide resistance mechanisms in the two-spotted spider mite Tetranychus urticae and other important Acari: A review. Insect Biochemistry and Molecular Biology 40: 563-572. DOI: 10.1016/j.ibmb.2010.05.008.

Van Pottelberge S., Van Leeuwen T., Van Amermaet K., Tirry L. 2008. Induction of cytochrome P450 monooxygenase activity in the two-spotted spider mite Tetranychus urticae and its influence on acaricide toxicity. Pesticide Biochemistry and Physiology 91: 128-133. DOI: 10.1016/j.pestbp.2008.03.005.

Van Pottelberge S., Van Leeuwen T., Nauen R., Tirry L. 2009. Resistance mechanisms to mitochondrial electron transport inhibitors in a field-collected strain of Tetranychus urticae Koch (Acari: Tetranychidae). Bulletin of Entomological Research 99: 23-31. DOI: 10.1017/s0007485308006081.

Yoshioka T., Yano S. 2014. Do Tetranychus urticae males avoid mating with familiar females? Journal of Experimental Biology 217: 2297-2300. DOI: 10.1242/jeb.098277. 